Acta Crystallographica Section B

Structural

Science

ISSN 0108-7681

\title{
Extended structures of polyiodide salts of transition metal macrocyclic complexes
}

The structures of five polyiodide salts, $\left[\mathrm{Co}\left([9] \mathrm{aneS}_{3}\right)_{2}\right] \mathrm{I}_{11}(1)$, $\left[\mathrm{Ni}\left([9] \mathrm{aneS}_{3}\right)_{2}\right] \mathrm{I}_{6}(2),\left[\mathrm{Ni}\left([9] \mathrm{aneS}_{3}\right)_{2}\right] \mathrm{I}_{10}(3),\left[\operatorname{Pd}\left([12] \mathrm{aneS}_{4}\right)\right] \mathrm{I}_{6}$ (4) and $\left[\operatorname{Pd}\left([14] \mathrm{aneS}_{4}\right)\right] \mathrm{I}_{10} \cdot \mathrm{MeCN}(5)$, containing the template cations $\left[\mathrm{Co}\left([9] \mathrm{aneS}_{3}\right)_{2}\right]^{3+},\left[\mathrm{Ni}\left([9] \mathrm{aneS}_{3}\right)_{2}\right]^{2+},\left[\mathrm{Pd}\left([12] \mathrm{aneS}_{4}\right)\right]^{2+}$ and $\left[\mathrm{Pd}\left([14] \mathrm{aneS}_{4}\right)\right]^{2+}\left([9] \mathrm{aneS}_{3}=1,4,7\right.$-trithiacyclononane, $[12] \mathrm{aneS}_{4}=1,4,7,10$-tetrathiacyclododecane, [14]aneS $\mathrm{a}_{4}=$ 1,4,8,11-tetrathiacyclotetradecane) exhibit a range of polyiodide and polyanionic framework structures. In (1) the charge on the $\mathrm{Co}^{\mathrm{III}}$ cation is balanced by three $\mathrm{I}_{3}^{-}$anions, which along with a neutral di-iodine molecule form $\mathrm{I}_{11}^{3-}$ rings in an extended structure comprising undulating chains of alternating $\mathrm{I}_{11}^{3-}$ rings and complex cations. In (2) the complex cation is linked to two tri-iodide anions by S...I interactions into well separated sheets of cations and anions, while in (3), $\mathrm{I}_{5}^{-}$anions are linked by I. . I interactions into helices which are cross-

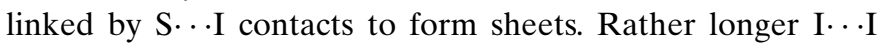
contacts in (4) assemble $\mathrm{I}_{3}^{-}$ions into $2 \times 2$ rods, which are linked into a three-dimensional network by $\mathrm{S}$. . I contacts. In (5) the $\mathrm{N}$ atom of the acetonitrile solvent molecule forms an array of four weak $\mathrm{C}-\mathrm{H} \cdots \mathrm{N}$ hydrogen bonds to the macrocycle. The extended structure comprises corrugated zigzag chains of polyiodide rings formed by linked $\mathrm{I}_{5}^{-}$units; the complex cations are attached to the polyiodide network by S. . I contacts, which link the chains to form layers.

\section{Introduction}

It is well known that $I_{2}$ is the dihalogen with the highest ability to catenate into oligomeric polyanions, which can assume a wide range of structural motifs (Svenson \& Kloo, 2003; Aragoni et al., 2003). Most of the known polyiodides have the general formula $\left(\mathrm{I}_{2 m+n}\right)^{n-}$, which formally implies the addition of $m \mathrm{I}_{2}$ molecules to $n$ iodide ions. Examples of small polyiodides belonging to this family, such as $\mathrm{I}_{3}^{-}, \mathrm{I}_{4}^{2-}$ and $\mathrm{I}_{5}^{-}$, are numerous in the literature, but the occurrence of discrete $\mathrm{I}_{2^{-}}$ rich higher polyiodides becomes steadily rarer as $m$ and $n$ increase (Svenson \& Kloo, 2003; Blake, Devillanova, Gould et al., 1998). All known higher polyiodides from $\mathrm{I}_{7}^{-}$to $\mathrm{I}_{22}^{4-}$ can be considered to be derived from the donor-acceptor interaction of asymmetric $\mathrm{I}_{3}^{-}$and/or $\mathrm{I}^{-}$with $\mathrm{I}_{2}$ molecules that are slightly elongated $\left[\mathrm{I}-\mathrm{I} \simeq 2.75-2.80 \AA,\left(\mathrm{I}_{3}^{-}\right) \mathrm{I}-\mathrm{I}_{2} \simeq 3.2-3.6 \AA\right]$ and can therefore be regarded as weak or medium-weak adducts of the type $\left[\left(\mathrm{I}^{-}\right)_{n-y^{\cdot}}\left(\mathrm{I}_{3}^{-}\right)_{y} \cdot\left(\mathrm{I}_{2}\right)_{m-y}\right]$. Some of these polyiodides are present in the crystal lattice as discrete aggregates, but they frequently form polymeric chains or extended two- or three-dimensional networks in the polyanionic matrix via cross-linking, soft-soft I...I secondary interactions: these generally range in length from $3.6 \AA$ up to the van der Waals sum for two iodine atoms (4.3 $\AA$; Kirin, 1987). The identification of the basic polyiodide unit can become arbitrary
Received 25 July 2006 Accepted 9 October 2006
(C) 2007 International Union of Crystallography Printed in Singapore - all rights reserved 
(Svenson \& Kloo, 2003; Blake, Devillanova, Gould et al., 1998). However, an I-I distance of $c a 3.6 \AA$ is commonly considered to be the borderline for the identification of the basic polyiodide unit in extended multi-dimensional polyanionic networks (Svenson \& Kloo, 2003; Aragoni et al., 2003): values lower than $3.6 \AA$ therefore identify the polyiodide unit, while values higher than this limit should be considered to be contacts between polyiodide units. Following this criterion, we have recently described several unusual multi-dimensional polyiodide arrays, obtained with a variety of metal complex cations (Horn, Blake, Champness, Garau et al., 2003; Horn, Blake, Champness, Lippolis \& Schröder, 2003; Aragoni et al., 2004), and in particular with metal thioether macrocyclic complexes (Blake et al., 1995; Blake, Devillanova, Gould et al., 1998; Blake, Li, Lippolis, Parsons \& Schröder, 1998; Blake, Li, Lippolis, Parsons, Radek \& Schröder, 1998) and free ligands (Blake, Devillanova, Garau et al., 1998) as templating agents. Metal complexes of such ligands were chosen as templates in order to achieve control over the architecture of the resultant polyiodide arrays because the shape, size and charge of the complex cations can be readily tuned by altering the metal ion or the macrocyclic ligand. Indeed, these features of the counter-cation are considered to play an important role in determining the solid-state organization of the associated polyiodide anion. Furthermore, other structural factors such as $\mathrm{S} \cdot \cdot \mathrm{I}$ and $M^{+} \cdot X^{-} \cdot \mathrm{I}_{2}(X=$ halogen $)$ interactions involving the templating metal complex may also play a crucial role in achieving control over the architecture of the resulting polyiodide network (Svenson \& Kloo, 2003; Blake, Devillanova, Garau et al., 1998; Blake, Devillanova, Gould et al., 1998; Blake, Gould, Li et al., 1998; Blake, Li, Lippolis et al., 1998; Blake, Li, Lippolis, Parsons \& Schröder, 1998; Blake, Lippolis, Parsons \& Schröder, 1998).

Polyiodide catenation has been shown to produce networks of varying topology by employing as templates a range of complex metal thioether cations differing in charge, shape and size. We have been able to draw some provisional conclusions:

(i) $\mathrm{BF}_{4}^{-}$or $\mathrm{PF}_{6}^{-}$metal salts in combination with excess diiodine generally result in the self-assembly of polyiodide species, while metathesis reactions using preformed $\mathrm{I}_{3}^{-}$or $\mathrm{I}_{5}^{-}$ ions generally yield isolated polyiodide units, typically triiodides;

(ii) the shape and charge of the cation direct the transfer of geometrical properties to the polyiodide network;

(iii) long S $\cdots \mathrm{I}$ and $M \cdots \mathrm{I}$ contacts favour lower dimensionality in polyiodide networks, the geometry of which differ from those predicted solely from the shape of the complex cation template;

(iv) the formation of higher-dimensional polyiodide networks is often impeded by the presence of S. .I and $M \cdots$ I contacts common in the products of metathesis.

One of our key objectives in this work was to determine whether these provisional conclusions are more generally valid. We have pursued this by using the complex cations $\left[\mathrm{Co}\left([9] \mathrm{aneS}_{3}\right)_{2}\right]^{3+}, \quad\left[\mathrm{Ni}\left([9] \mathrm{aneS}_{3}\right)_{2}\right]^{2+}, \quad\left[\operatorname{Pd}\left([12] \mathrm{aneS}_{4}\right)\right]^{2+}$ and $\left[\mathrm{Pd}\left([14] \mathrm{aneS}_{4}\right)\right]^{2+}$ as cationic templating agents for the selfassembly of polyiodide anions. The synthesis, structural features and FT-Raman spectroscopy of compounds corresponding to the formulations $\left[\mathrm{Co}\left([9] \mathrm{aneS}_{3}\right)_{2}\right] \mathrm{I}_{11}$ (1), $\left[\mathrm{Ni}\left([9] \mathrm{aneS}_{3}\right)_{2}\right] \mathrm{I}_{6}(2),\left[\mathrm{Ni}\left([9] \mathrm{aneS}_{3}\right)_{2}\right] \mathrm{I}_{10}(3),\left[\mathrm{Pd}\left([12] \mathrm{aneS}_{4}\right)\right] \mathrm{I}_{6}$ (4) and $\left[\operatorname{Pd}\left([14] \mathrm{aneS}_{4}\right)\right] \mathrm{I}_{10} \cdot \mathrm{MeCN}(5)$ are described in this paper.

\section{Experimental}

\subsection{General procedures}

All reagents and solvents were purchased from Aldrich and used without further purification. $\left[\mathrm{Co}\left([9] \mathrm{aneS}_{3}\right)_{2}\right]\left(\mathrm{PF}_{6}\right)_{2}$, $\left[\mathrm{Ni}\left([9] \mathrm{aneS}_{3}\right)_{2}\right]\left(\mathrm{BF}_{4}\right)_{2}, \quad\left[\mathrm{Ni}\left([9] \mathrm{aneS}_{3}\right)_{2}\right]\left(\mathrm{PF}_{6}\right)_{2}$ (Setzer et al., 1983), $\left[\operatorname{Pd}\left([12] \mathrm{aneS}_{4}\right)\right]\left(\mathrm{PF}_{6}\right)_{2}$ and $\left[\operatorname{Pd}\left([14] \mathrm{aneS}_{4}\right)\right]\left(\mathrm{PF}_{6}\right)_{2}($ Bell et al., 1987) were prepared according to literature methods.

FT-Raman spectra (resolution $4 \mathrm{~cm}^{-1}$ ) were recorded at room temperature on a Bruker RFS 100 FTR spectrometer fitted with an In-Ga-As detector and operating with an excitation frequency of $1064 \mathrm{~nm}$. Power levels of the Nd:YAG laser source varied between 20 and $100 \mathrm{~mW}$. The solid samples were packed into a suitable cell and fitted into the compartment designed for $180^{\circ}$ scattering geometry. The number in parentheses following each wavenumber value represents the intensity of the peak relative to the strongest $(=100)$.

\subsection{Synthesis of $\left[\mathrm{Co}\left([9] \operatorname{aneS}_{3}\right)_{2}\right] \mathbf{l}_{11}$ (1)}

A mixture of $\left[\mathrm{Co}\left([9] \mathrm{aneS}_{3}\right)_{2}\right]\left(\mathrm{PF}_{6}\right)_{2}(15.0 \mathrm{mg}, 0.0210 \mathrm{mmol})$ and $\mathrm{I}_{2}(29.4 .0 \mathrm{mg}, 0.116 \mathrm{mmol})$ in $\mathrm{MeCN}(5 \mathrm{ml})$ was stirred at room temperature for $1 \mathrm{~h}$ and subsequently allowed to stand. After a few days, dark blocks of the compound were formed (24.8 $\mathrm{mg}, 65 \%$ yield). Elemental analysis: found (calc. for $\mathrm{C}_{12} \mathrm{H}_{24} \mathrm{CoI}_{11} \mathrm{~S}_{6}$ ) C 7.90 (7.94), H 1.31 (1.33), S 10.60 (10.59)\%. FT-Raman (500-10 cm $\left.\mathrm{cm}^{-1}\right)$ : 168.2 (100), 149.9 (68), 109.5 (61) $\mathrm{cm}^{-1}$.

\subsection{Synthesis of $\left.\left[\mathrm{Ni}\left([9] \mathrm{aneS}_{3}\right)_{2}\right]\right]_{6}(2)$}

To a solution of $\left[\mathrm{Ni}\left([9] \mathrm{aneS}_{3}\right)_{2}\right]\left(\mathrm{BF}_{4}\right)_{2} \quad(20.0 \mathrm{mg}$, $0.0334 \mathrm{mmol})$ in $\mathrm{MeCN}(4 \mathrm{ml})$ was added a solution of ${ }^{n} \mathrm{Bu}_{4} \mathrm{NI}_{3}$ [prepared by mixing a solution of ${ }^{n} \mathrm{Bu}_{4} \mathrm{NI}(24.7 \mathrm{mg}$, $0.0668 \mathrm{mmol})$ in $\mathrm{MeCN}(2 \mathrm{ml})$ and a solution of $\mathrm{I}_{2}(17.0 \mathrm{mg}$, $0.0668 \mathrm{mmol})$ in $\mathrm{MeCN}(2 \mathrm{ml})]$. The mixture obtained was allowed to stand and after several hours deep red blocks of the title compound appeared ( $25.71 \mathrm{mg}, 65.2 \%$ yield). Elemental analysis: found (calc. for $\mathrm{C}_{12} \mathrm{H}_{24} \mathrm{I}_{6} \mathrm{NiS}_{6}$ ) C 12.15 (12.20), H 2.10 (2.05), S 16.32 (16.29)\%. FT-Raman (500-10 $\left.\mathrm{cm}^{-1}\right)$ : 129 (26), $113(100) \mathrm{cm}^{-1}$.

\subsection{Synthesis of $\left[\mathrm{Ni}\left([9] \mathrm{aneS}_{3}\right)_{2}\right] \mathrm{I}_{10}$ (3)}

A mixture of $\left[\mathrm{Ni}\left([9] \mathrm{aneS}_{3}\right)_{2}\right]\left(\mathrm{PF}_{6}\right)_{2}(15.0 \mathrm{mg}, 0.0211 \mathrm{mmol})$ and $\mathrm{I}_{2}(26.8 \mathrm{mg}, 0.1055 \mathrm{mmol})$ in $\mathrm{MeCN}(5 \mathrm{ml})$ was stirred at room temperature for $1 \mathrm{~h}$ and subsequently allowed to stand. After a few days, dark blocks of the title compound were formed ( $21.4 \mathrm{mg}, 60 \%$ yield). Elemental analysis: found (calc. for $\left.\mathrm{C}_{12} \mathrm{H}_{24} \mathrm{I}_{10} \mathrm{NiS}_{6}\right)$ C 8.50 (8.54), H 1.41 (1.43), S 11.40 (11.39)\%. FT-Raman $\left(500-10 \mathrm{~cm}^{-1}\right): 164.2$ (100), 145.4 (93) $\mathrm{cm}^{-1}$. 


\subsection{Synthesis of $\left[\operatorname{Pd}\left([12] \operatorname{aneS}_{4}\right)\right] I_{6}(4)$}

To a solution of $\left[\mathrm{Pd}\left([12] \mathrm{aneS}_{4}\right)\right]\left(\mathrm{PF}_{6}\right)_{2} \quad(25.0 \mathrm{mg}$, $0.039 \mathrm{mmol})$ in $\mathrm{MeCN}(3 \mathrm{ml})$ was added a solution of ${ }^{n} \mathrm{Bu}_{4} \mathrm{NI}_{3}$ [prepared by mixing a solution of ${ }^{n} \mathrm{Bu}_{4} \mathrm{NI}(28.8 \mathrm{mg}$, $0.078 \mathrm{mmol})$ in $\mathrm{MeCN}(2 \mathrm{ml})$ and a solution of $\mathrm{I}_{2}(19.8 \mathrm{mg}$, $0.078 \mathrm{mmol})$ in $\mathrm{MeCN}(2 \mathrm{ml})]$. The mixture obtained was allowed to stand and after several hours deep red columns of the title compound $(12.97 \mathrm{mg}, 30 \%$ yield) were formed. The crystals were separated from the mother liquor by filtration, and further crystals of the same compound could be obtained from the solution on standing. Elemental analysis: found (calc. for $\left.\mathrm{C}_{8} \mathrm{H}_{16} \mathrm{I}_{6} \mathrm{PdS}_{4}\right) \quad \mathrm{C} 8.63$ (8.67), $\mathrm{H} 1.43$ (1.45), $\mathrm{S} 11.55$ $(11.57) \%$. FT-Raman $\quad\left(500-10 \mathrm{~cm}^{-1}\right): 125 \quad$ (30), 110 (100) $\mathrm{cm}^{-1}$.

\subsection{Synthesis of $\left[\operatorname{Pd}\left([14] \mathrm{aneS}_{4}\right)\right] \mathrm{l}_{10} \cdot \mathrm{MeCN}(5)$}

A mixture of $\left[\mathrm{Pd}\left([14] \mathrm{aneS}_{4}\right)\right]\left(\mathrm{PF}_{6}\right)_{2}(20.0 \mathrm{mg}, 0.030 \mathrm{mmol})$ and $\mathrm{I}_{2}(38.1 \mathrm{mg}, 0.15 \mathrm{mmol})$ in $\mathrm{MeCN}(5 \mathrm{ml})$ was stirred at room temperature for $1 \mathrm{~h}$ and then allowed to stand. After a few days, dark blocks of the title compound were formed (25.3 $\mathrm{mg}, 50 \%$ yield). Elemental analysis: found (calc. for $\mathrm{C}_{12} \mathrm{H}_{23} \mathrm{I}_{10} \mathrm{NPdS}_{4}$ ) C 8.53 (8.55), H 1.33 (1.38), N 0.89 (0.83), S 7.58 (7.61)\%. FT-Raman $\left(500-10 \mathrm{~cm}^{-1}\right)$ : 168.9 (89), 163.2 (100), 154.5 (75), $115.7(61) \mathrm{cm}^{-1}$.

\subsection{Crystal structure determinations}

Experimental data are given in Table 1. ${ }^{\mathbf{1}}$ Diffraction data for (1)-(5) were collected on Stoe Stadi-4 four-circle diffractometers equipped with Oxford Cryosystems open-flow nitrogen cryostats operating at 150 (2) K (Cosier \& Glazer, 1986) as $\omega-\theta$ scans using a learnt-profile method (Clegg, 1981). Corrections for absorption were applied either by an integration method based on face-indexing (Stoe \& Cie, 1996b) or by $\psi$ scans (North et al., 1968). The structures were solved by direct methods (Sheldrick, 1990; Altomare et al., 1994) and developed by iterative cycles of least-squares refinement and difference-Fourier synthesis (Sheldrick, 1998). H atoms were placed geometrically and treated in refinement as part of a riding model, with the exception of the solvent methyl $\mathrm{H}$ atoms in (5), which were located from a circular differenceFourier synthesis and refined as part of a rigid rotating group. The structure analyses were routine except in the case of (4), where the structure exhibits co-facial disorder of the entire $\left[\operatorname{Pd}\left([12] \mathrm{aneS}_{4}\right)\right]^{2+}$ cation: the macrocyclic ring components occupy a common plane from which the metal sites are displaced in opposite directions. The disorder was modelled as a major [0.824 (3)] and a minor [0.176 (3)] component. The atoms of the major component were refined with anisotropic displacement parameters, while the $\mathrm{C}$ atoms of the minor component were refined with a common $U_{\text {iso }}$ of 0.028 (9) $\AA^{2}$. A distance restraint of 1.54 (1) $\AA$ was applied to all $\mathrm{C}-\mathrm{C}$ distances in the structure and similarity restraints were applied between the two disorder components. Illustrations were

\footnotetext{
${ }^{1}$ Supplementary data for this paper are available from the IUCr electronic archives (Reference: GP5013). Services for accessing these data are described at the back of the journal.
}

produced using SHELXTL (Bruker, 2001) and MERCURY (Macrae et al., 2006).

\section{Discussion}

\subsection{Synthetic considerations}

Different synthetic procedures for the preparation of polyiodides have been reported in the literature, the most common route involving the addition of different amounts of $\mathrm{I}_{2}$ to an iodide or tri-iodide salt of the appropriate cation in a single phase (Tebbe \& Buchem, 1997). Alternatively, a metathesis reaction can be employed, especially for the synthesis of small polyiodides, in which preformed $\mathrm{I}_{3}^{-}$or $\mathrm{I}_{5}^{-}$is reacted with a salt of the desired cation: in this case it is rare for a polyiodide species different from that used as the starting material to occur in the final product (Blake, Gould et al., 1999). In our attempts to synthesize extended polyiodide networks, we have mainly reacted the $\mathrm{PF}_{6}^{-}$or $\mathrm{BF}_{4}^{-}$salt of the metal complex cation with excess $\mathrm{I}_{2}$ in a single phase, generally in $\mathrm{MeCN}$ solution. In this way the driving force of the process is the template effect of the metal complex with the preferred polyiodide species being formed by self-assembly. In this last synthetic method, the identity of the species responsible for the reduction of di-iodine and the kinetic mechanism leading to the formation of polyiodides has not been established. For the compounds reported herein, we have used both metathesis reactions and reactions of excess $\mathrm{I}_{2}$ with $\mathrm{PF}_{6}^{-}$or $\mathrm{BF}_{4}^{-}$salts of the complex cation. Interestingly, in the synthesis of $\left[\mathrm{Co}\left([9] \mathrm{aneS}_{3}\right)_{2}\right]^{3+} \cdot 3 \mathrm{I}_{3}^{-} \cdot \mathrm{I}_{2}$ (1) starting from $\left[\mathrm{Co}\left([9] \mathrm{aneS}_{3}\right)_{2}\right]-$ $\left(\mathrm{PF}_{6}\right)_{2}$ and excess $\mathrm{I}_{2}$ we observed the oxidation of the metal centre from $\mathrm{Co}^{\mathrm{II}}$ to $\mathrm{Co}^{\mathrm{III}}$. This represents the first example of the self-assembly of a polyiodide species at a thioethermacrocycle metal complex template concomitant with oxidation of the metal centre.

\subsection{Molecular geometry}

Molecular geometry parameters for (1)-(5) are listed in Table 2.

3.2.1. $\left[\mathrm{Co}\left(\mathrm{C}_{6} \mathrm{H}_{12} \mathrm{~S}_{3}\right)_{2}\right]^{3+} \cdot \mathbf{3} \mathbf{I}_{3}^{-} \cdot \mathbf{I}_{2}$ (1). In the structure of $\left[\mathrm{Co}\left(\mathrm{C}_{6} \mathrm{H}_{12} \mathrm{~S}_{3}\right)_{2}\right]^{3+} \cdot 3 \mathrm{I}_{3}^{-} \cdot \mathrm{I}_{2}\left[(1)\right.$; see Fig. 1] the $\left[\mathrm{Co}\left([9] \mathrm{aneS}_{3}\right)_{2}\right]^{3+}$ cation lies on a crystallographic inversion centre, one of the tri-iodide anions lies across a twofold axis while the other lies in a general position, and the iodine molecule lies across another twofold axis. The three independent $\mathrm{Co}-\mathrm{S}$ distances of 2.242 (2), 2.252 (2) and 2.259 (2) $\AA$ are very similar and the $\mathrm{S}-\mathrm{Co}-\mathrm{S}$ angles lie close to $90^{\circ}$, conferring an octahedral coordination on the $\mathrm{Co}^{\mathrm{III}}$ centre which is similar to that seen in $\left[\mathrm{Co}\left(\mathrm{C}_{6} \mathrm{H}_{12} \mathrm{~S}_{3}\right)_{2}\right]\left(\mathrm{ClO}_{4}\right)_{3}$ (Küppers et al., 1986). The tri-iodide anion across the twofold axis exhibits two I1 $-\mathrm{I} 2$ distances of 2.9419 (14) $\AA$ and a near-linear I-I-I angle of 179.21 (4) ${ }^{\circ}$, while the second anion shows inequivalent $\mathrm{I}-\mathrm{I}$ distances of 2.8225 (10) $\AA$ for I4-I5 and 3.0593 (11) $\AA$ for I3-I4, with an $\mathrm{I}-\mathrm{I}-\mathrm{I}$ angle of $175.75(3)^{\circ}$. The variation in these distances is related to the different contacts formed by iodine centres (see \$3.3.1 below). Likewise, the iodine molecule shows an I-I distance of 2.7577 (16) A, somewhat longer than the value of 
Table 1

Experimental details.

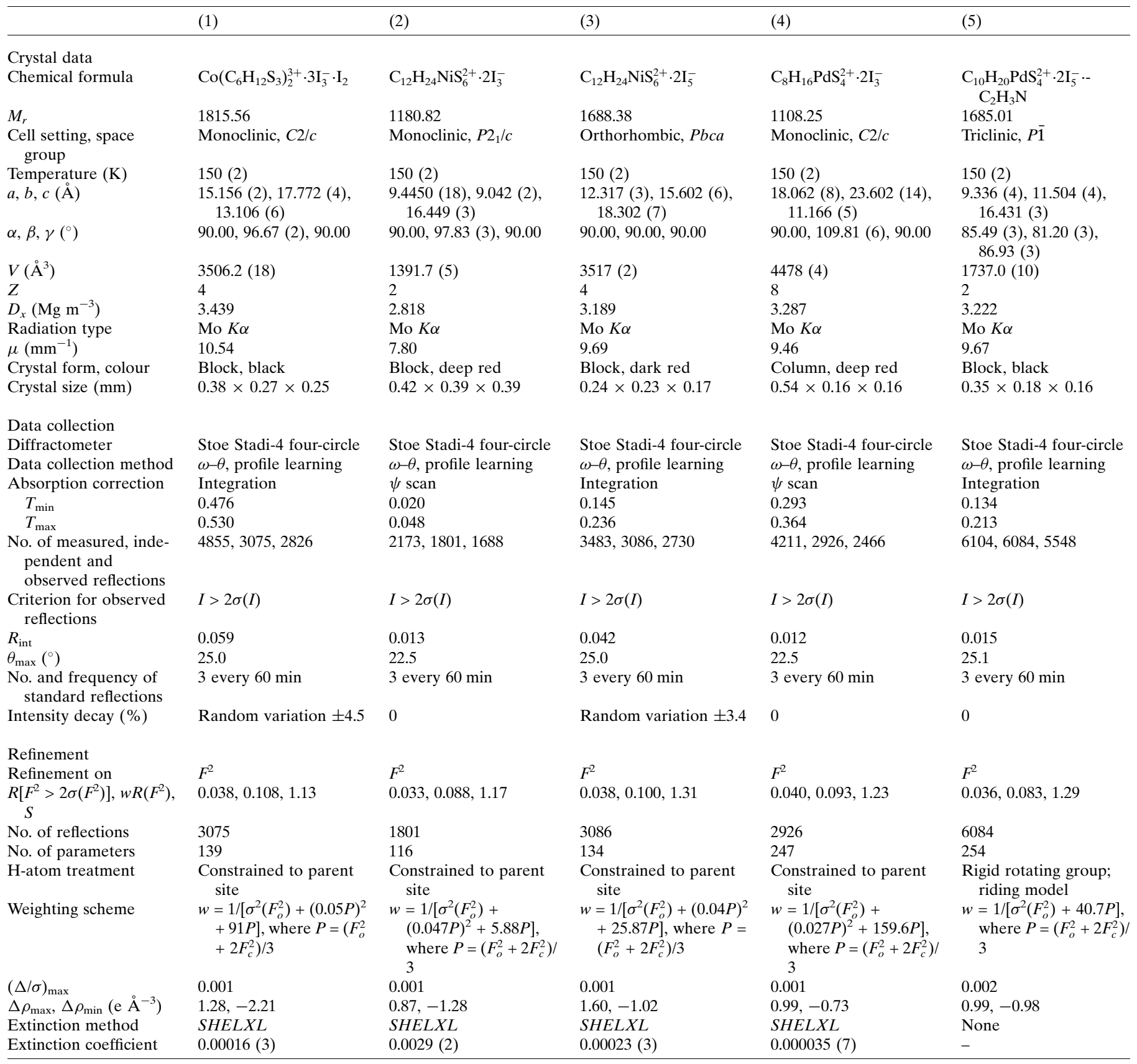

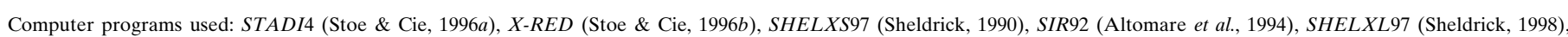
MERCURY (Macrae et al., 2006), enCIFer (Allen et al., 2004), PLATON (Spek, 2003).

2.715 (6) $\AA$ in crystalline di-iodine at $110 \mathrm{~K}$ (van Bolhuis et al., 1967).

3.2.2. $\left[\mathrm{Ni}\left(\mathrm{C}_{6} \mathrm{H}_{12} \mathrm{~S}_{3}\right)_{2}\right]^{2+} \cdot \mathbf{2 I}_{3}{ }^{-} \quad$ (2). The octahedral $\left[\mathrm{Ni}\left([9] \mathrm{aneS}_{3}\right)_{2}\right]^{2+}$ cation in $\left[\mathrm{Ni}\left(\mathrm{C}_{6} \mathrm{H}_{12} \mathrm{~S}_{3}\right)_{2}\right]^{2+} \cdot 2 \mathrm{I}_{3}{ }^{-}[(2)$, see Fig. 2] occupies a crystallographic inversion centre, with the atoms of the tri-iodide anion in general positions. The three independent $\mathrm{Ni}-\mathrm{S}$ distances are similar at 2.4020 (17), 2.3978 (17) and 2.3799 (16) $\AA$, and the $\mathrm{S}-\mathrm{Ni}-\mathrm{S}$ angles $[88.56(6)$, $89.06(6)$ and $88.83(6)^{\circ}$ ] are approximately $90^{\circ}$. These geometric features closely match previously reported values in structures containing the $\left[\mathrm{Ni}\left([9] \mathrm{aneS}_{3}\right)_{2}\right]^{2+}$ cation with a range of anions (Setzer et al., 1983; Blake et al., 2001; Nishijo et al., 2004), where the $\mathrm{Ni}-\mathrm{S}$ distances range between 2.371 (1) and 2.408 (2) $\AA$. The I-I distances [I1 - I2 2.8959 (10), I1 - I3 2.9433 (10) $\AA$ ] are inequivalent due to the involvement of $\mathrm{I} 3$ in an intermolecular S ...I interaction, and the I-I-I angle is $178.25(2)^{\circ}$. Although its cobalt(II) analogue (Blake, Lippolis et al.,1998) exhibits a much wider range of $M-\mathrm{S}$ bond lengths [2.2742 (10), 2.2959 (11) and $2.4088(11) \AA$ ], the two structures are isomorphous. 
Table 2

Selected molecular geometry parameters $\left(\AA,^{\circ}\right)$ for (1)-(5).

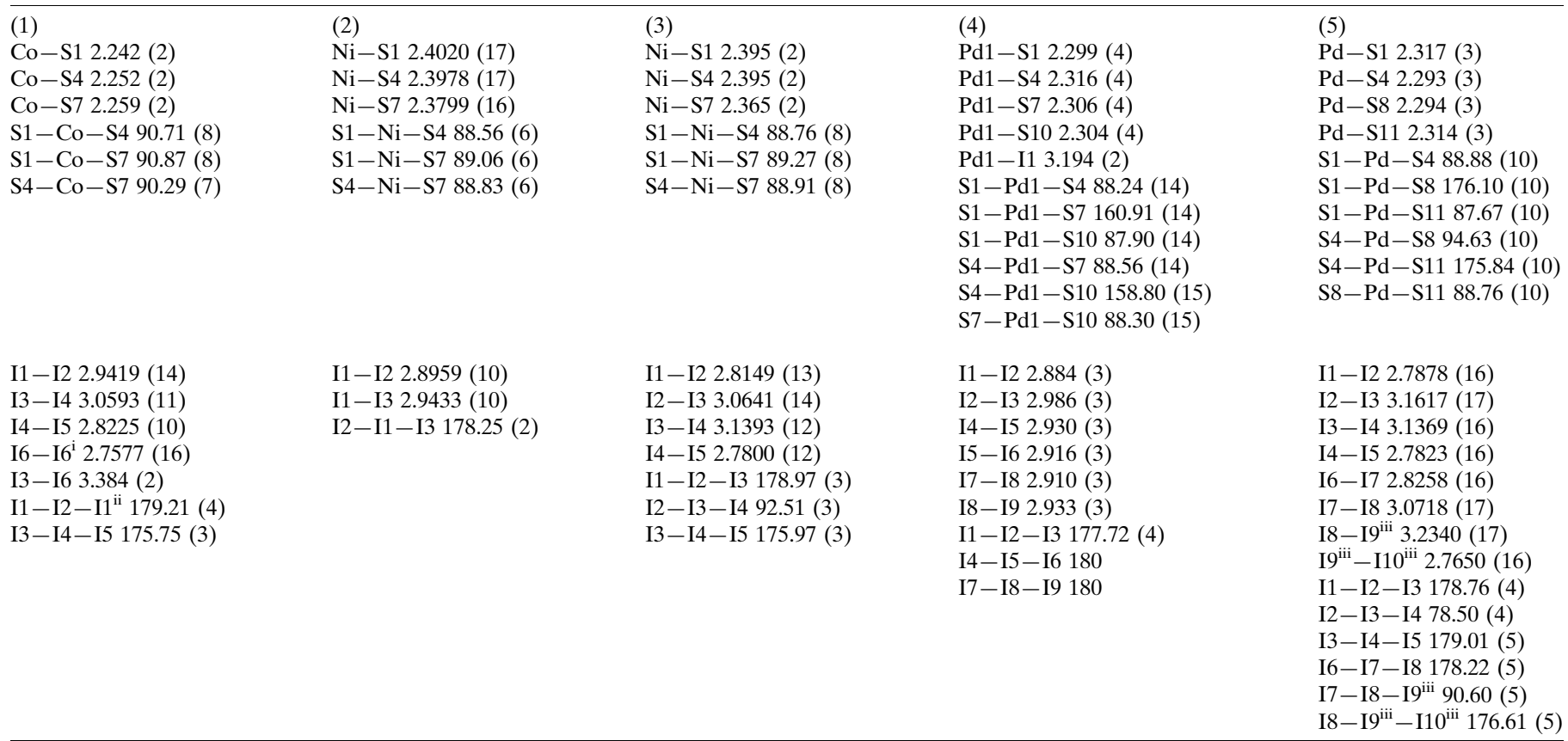

Symmetry codes: (i) $1-x, y, \frac{3}{2}-z$; (ii) $-x, y, \frac{3}{2}-z$; (iii) $1-x, 1-y, 1-z$.

3.2.3. $\left[\mathrm{Ni}\left(\mathrm{C}_{6} \mathrm{H}_{12} \mathrm{~S}_{3}\right)_{2}\right]^{2+} \cdot 2 \mathrm{I}_{5}^{-}$(3). This structure also contains an octahedral $\left[\mathrm{Ni}\left([9] \mathrm{aneS}_{3}\right)_{2}\right]^{2+}$ cation located on a crystallographic inversion centre, with the atoms of the $\mathrm{I}_{5}^{-}$anion in general positions (Fig. 3). The $\mathrm{Ni}-\mathrm{S}$ distances [2.365 (2), 2.395 (2) and 2.395 (2) $\AA$ ] again lie in the expected range, as do the $\mathrm{S}-\mathrm{Ni}-\mathrm{S}$ angles [88.76 (8), $88.91(8)$ and $\left.89.27(8)^{\circ}\right]$. The anion exhibits the pattern of alternating longer and shorter I-I distances, one angle of around $90^{\circ}$ and two of around $180^{\circ}$, which are typical of a distorted $\mathrm{V}$-shaped $\mathrm{I}_{5}^{-}$ fragment that can be described as a weak adduct of the type $\left[\mathrm{I}^{-} \cdot\left(\mathrm{I}_{2}\right)_{2}\right]$ between an iodide ion and two di-iodine molecules

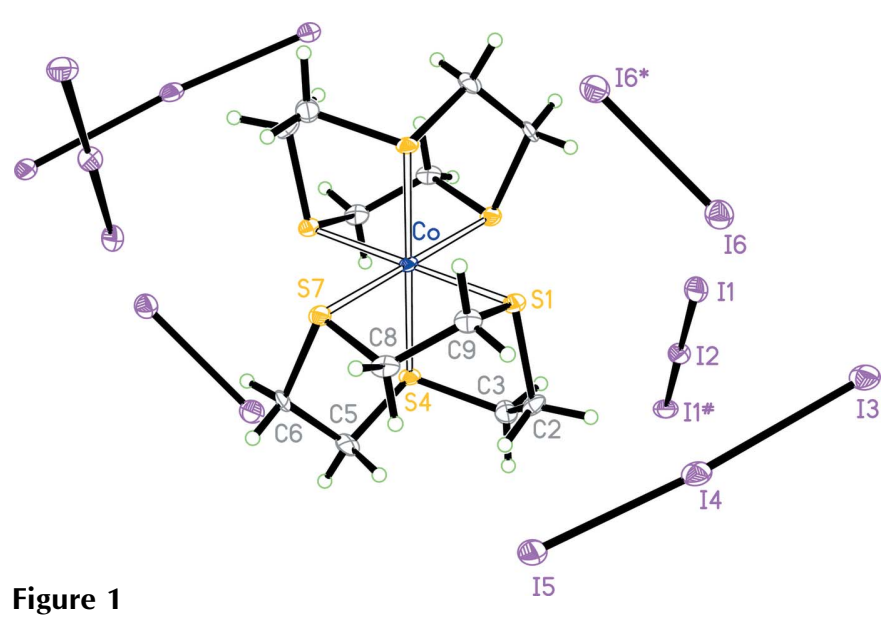

A view of the structure of (1) with atom-numbering scheme and ellipsoids drawn at the $50 \%$ probability level. The second macrocycle is generated from the labelled one by the symmetry operation $\left(\frac{1}{2}-x, \frac{1}{2}-y, 1-z\right)$. Symmetry codes: \# $-x, y, \frac{3}{2}-z ; * 1-x, y, \frac{3}{2}-z$.
(Svenson \& Kloo, 2003; Blake, Devillanova, Gould et al., 1998; Blake, Gould et al., 1999).

3.2.4. $\left[\mathbf{P d}\left(\mathbf{C}_{\mathbf{8}} \mathbf{H}_{\mathbf{1 6}} \mathbf{S}_{\mathbf{4}}\right)\right]^{\mathbf{2 +}} \cdot \mathbf{2} \mathrm{I}_{3}^{-}$(4). This structure exhibits cofacial disorder with a major $[0.824(3)]$ and a minor $[0.176(3)]$ component. The most likely reason for this disorder is the apparently rather poor fit between the cation and the polyiodide network. The following discussion refers to the major component only. The $\left[\operatorname{Pd}\left([12] \mathrm{aneS}_{4}\right)\right]^{2+}$ macrocyclic cation and the attached tri-iodide occupy general positions with the remaining tri-iodides lying along crystallographic twofold axes. The $\mathrm{Pd}^{\mathrm{II}}$ centre occupies a distorted square-planar coordination environment with $\mathrm{Pd}-\mathrm{S}$ distances of 2.299 (4)2.316 (4) $\AA$ and cis-S-Pd-S angles of 87.90 (14)-88.56 (14) ${ }^{\circ}$ (Fig. 4). The cavity of the macrocycle is too small to accommodate the $\mathrm{Pd}^{\mathrm{II}}$ or $\mathrm{Pt}^{\mathrm{II}}$ cation (Blake et al., 1994) and the metal cation sits out of the plane of the four S donors by 0.403 (2) $\AA$ in the direction of a weakly coordinating axial tri-iodide [Pd1-

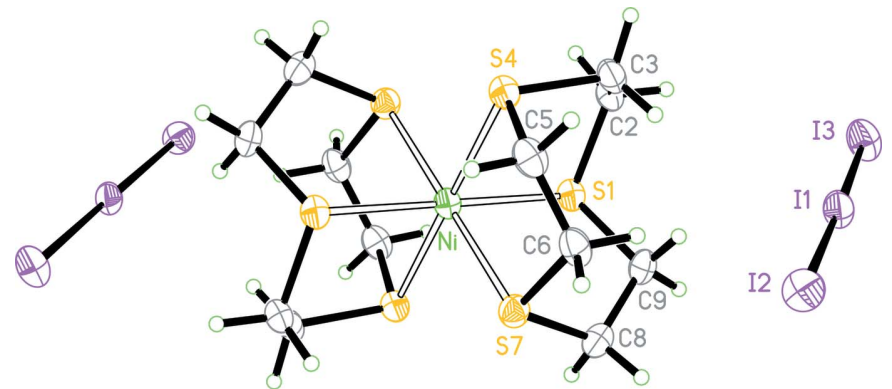

Figure 2

A view of the structure of (2) with atom-numbering scheme and ellipsoids drawn at the $50 \%$ probability level. The second macrocycle is generated from the labelled one by the symmetry operation $(2-x,-y, 2-z)$. 


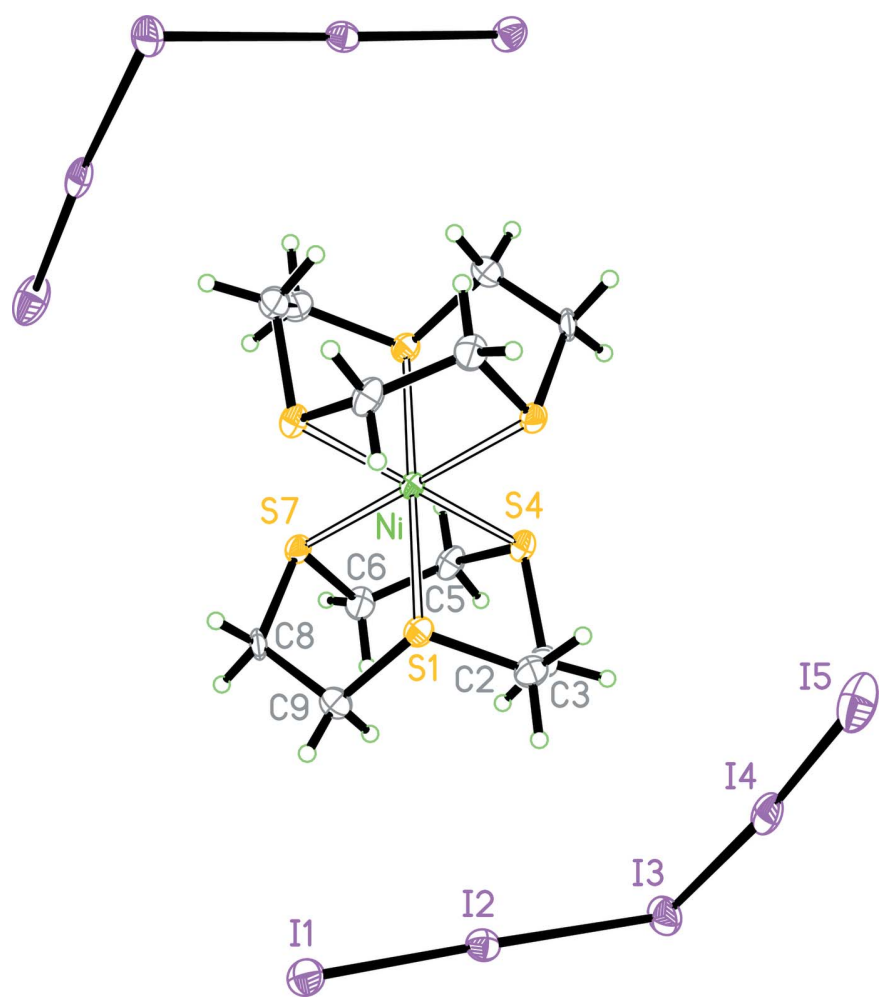

Figure 3

A view of the structure of (3) with atom-numbering scheme and ellipsoids drawn at the $50 \%$ probability level. The second macrocycle is generated from the labelled one by the symmetry operation $(1-x, 1-y, 1-z)$.

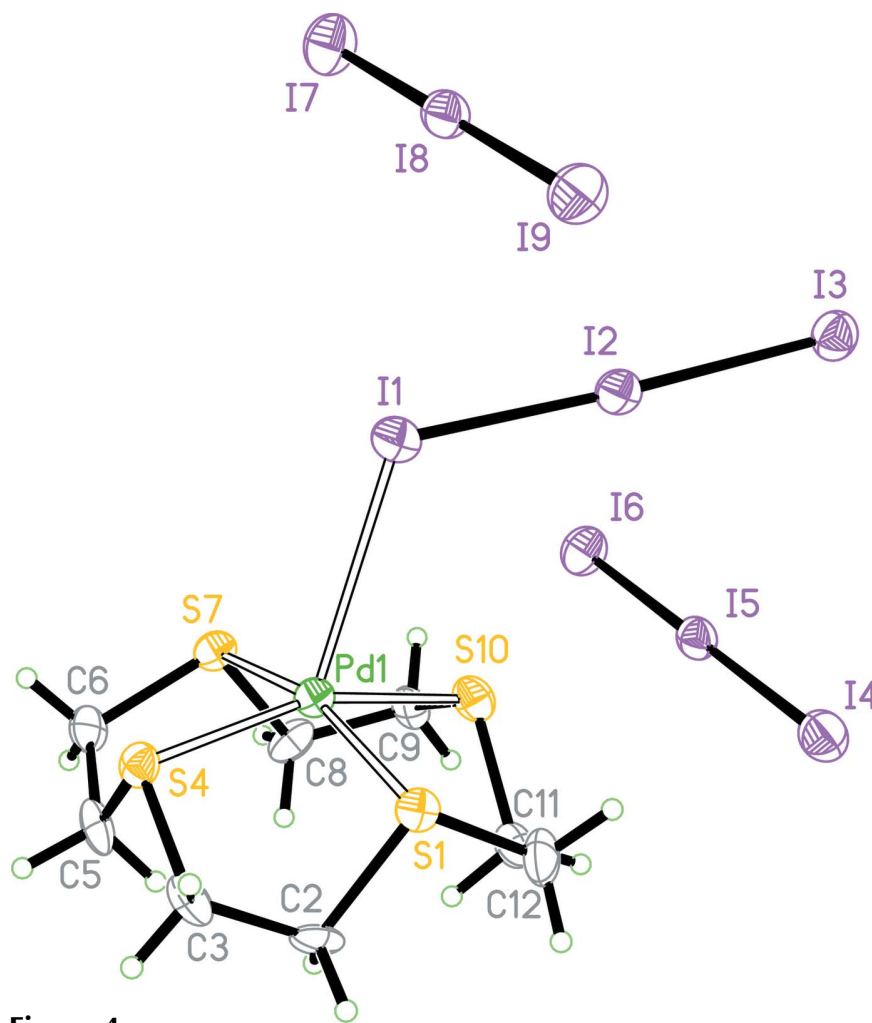

Figure 4

A view of the structure of (4) with atom-numbering scheme and ellipsoids drawn at the $50 \%$ probability level. Only the major disorder component is shown. The uncoordinated tri-iodides lie along crystallographic twofold axes.
I1 $3.194(2) \AA]$. The macrocycle adopts a [3333] square conformation with the $\mathrm{S}$ atoms placed along the edges, as expected for endo coordination by this ligand (Blake \& Schröder, 1990). The coordinated tri-iodide anion shows some asymmetry in its geometry [I1-I2 $2.884(3), \quad \mathrm{I} 2-\mathrm{I} 3$ 2.986 (3) $\AA, \mathrm{I} 1-\mathrm{I} 2-\mathrm{I} 3177.72(4)^{\circ}$ ], in contrast to the other anions which are linear by symmetry and where the distances are very similar [mean 2.920 (4) $\AA$ ] .

3.2.5. $\left[\mathrm{Pd}\left[\mathrm{C}_{10} \mathbf{H}_{20} \mathrm{PdS}_{4}\right)\right]^{2+} \cdot \mathbf{2}_{5}^{-} \cdot \mathbf{C}_{\mathbf{2}} \mathrm{H}_{3} \mathbf{N}$ (5). Within the $\left[\mathrm{Pd}\left([14] \mathrm{aneS}_{4}\right)\right]^{2+}$ macrocyclic cation, the $\mathrm{Pd}^{\mathrm{II}}$ centre occupies a distorted square-planar environment, with $\mathrm{Pd}-\mathrm{S}$ distances of 2.293 (3)-2.317 (3) $\AA$ and cis-S-Pd-S angles of 87.67 (10)$94.63(10)^{\circ}$ (Fig. 5). Although it is larger than in [12] $\mathrm{aneS}_{4}$, the cavity of the [14] $\mathrm{aneS}_{4}$ macrocycle still cannot fully accommodate the $\mathrm{Pd}^{\mathrm{II}}$ cation which lies slightly [0.040 (2) $\AA$ ] out of the plane of the four $\mathrm{S}$ donors. The $\mathrm{N}$ atom of the acetonitrile solvent molecule lies 3.395 (11) $\AA$ from the metal and approaches its less open face, suggesting that there is no significant $\mathrm{Pd} \cdots \mathrm{N}$ interaction. However, the nitrogen is well placed to form four weak hydrogen bonds $(\mathrm{N} \cdots \mathrm{H} 2.53-$ $2.62 \AA$; C $-\mathrm{H} \cdots \mathrm{N} 142-151^{\circ}$; see Table 3 ) with a $\mathrm{H}$ atom in one of the two methylene groups adjacent to each sulfur in the propyl linkages: given that these are likely to be the $\mathrm{H}$ atoms most activated to accept weak hydrogen bonds, we believe that these interactions are significant. The two $\mathrm{I}_{5}^{-}$anions have generally similar geometries but differ in detail, with I1-I5 being more symmetrical and displaying a much more acute central I-I-I angle $\left[78.50(4)^{\circ}\right]$ than I6-I10 [90.60 (4) $)^{\circ}$. These differences may be due in part to the different environments of the two anions: for example, I1 - I5 forms significant intermolecular contacts only through its terminal atoms, while I6-I10 also interacts through other I atoms (see §3.3.5). However, the $\mathrm{I}-\mathrm{I}$ distances indicate that $\left[\mathrm{I}^{-} \cdot 2 \mathrm{I}_{2}\right]$ is the best description for both $\mathrm{I}_{5}^{-}$anions, one (I1-I5) being V-shaped and the other (I6-I10) being L-shaped.

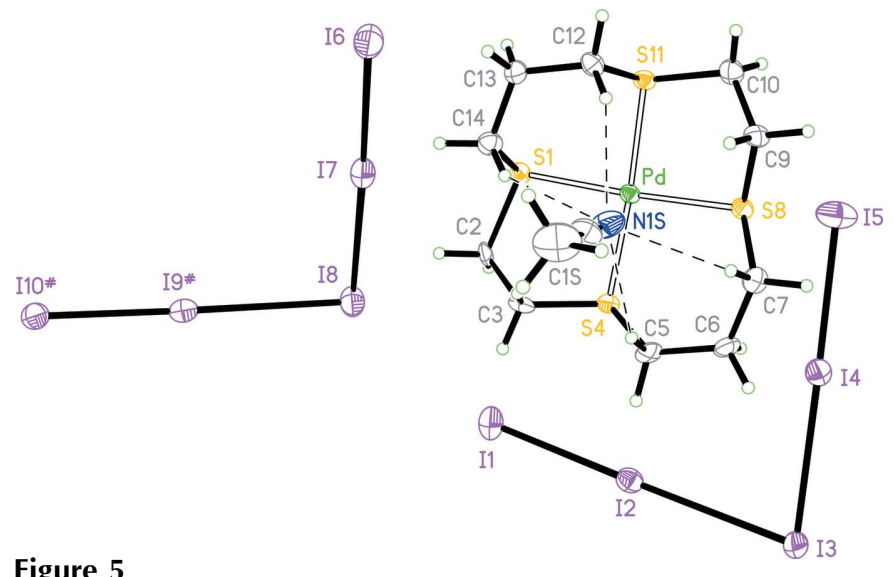

Figure 5

A view of the structure of (5) with atom-numbering scheme and ellipsoids drawn at the $50 \%$ probability level. The view is towards the less exposed face of the cation and the broken lines indicate $\mathrm{C}-\mathrm{H} \cdots \mathrm{N}$ interactions between the acetonitrile solvent molecule and the macrocycle. Symmetry code: \# $(1-x, 1-y, 1-z)$. 
Table 3

Intermolecular I $\cdots \mathrm{I}, \mathrm{S} \cdots \mathrm{I}$ and $\mathrm{CH} \cdots \mathrm{N}$ contacts $\left(\AA{ }^{\circ}\right)$ for $(1)-(5)$.

\begin{tabular}{|c|c|c|c|c|}
\hline (1) & (2) & (3) & (4) & (5) \\
\hline 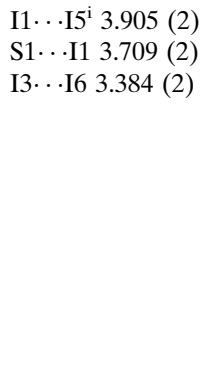 & $\begin{array}{l}\text { S7 } \cdots \mathrm{I} 3^{\mathrm{ii}} 3.769(2) \\
\text { S4 } \cdots \mathrm{I} 2^{\mathrm{iii}} 3.796(2) \\
\mathrm{S} 1 \cdots \mathrm{I} 3^{\mathrm{iv}} 3.983(2) \\
\mathrm{S} 7 \cdots \mathrm{I} 2^{\mathrm{v}} 3.970(2)\end{array}$ & $\begin{array}{l}\mathrm{I} 5 \cdots \mathrm{I} 1^{\mathrm{vi}} 3.799(2) \\
\mathrm{S} 4 \cdots 3^{\mathrm{vii}} 3.771(2)\end{array}$ & 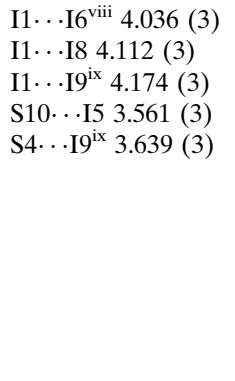 & $\begin{array}{l}\mathrm{I} 6 \cdots \mathrm{I} 10^{\mathrm{ix}} 3.543(2) \\
\mathrm{I} 5 \cdots \mathrm{I} 6^{\mathrm{ix}} 3.913(2) \\
\mathrm{I} 1 \cdots \mathrm{I} 6^{\mathrm{ix}} 4.179(2) \\
\mathrm{I} 1 \cdots \mathrm{I} 8^{\mathrm{x}} 3.693(2) \\
\mathrm{S} 1 \cdots \mathrm{I} 2^{\mathrm{xi}} 3.771(2) \\
\mathrm{S} 4 \cdots \mathrm{I} 2^{\mathrm{xii}} 3.775(2) \\
\mathrm{S} 8 \cdots \mathrm{I} 3^{\mathrm{xiii}} 3.754(2) \\
\mathrm{S} 8 \cdots \mathrm{I} 4^{\mathrm{xi}} 3.887(2) \\
\mathrm{C} 5 \mathrm{H} 5 A \cdots \mathrm{N} 1 \mathrm{~S} 2.62, \angle \mathrm{CHN} 144 \\
\mathrm{C} 7 \mathrm{H} 7 B \cdots \mathrm{N} 1 \mathrm{~S} 2.62, \angle \mathrm{CHN} 142 \\
\mathrm{C} 12 \mathrm{H} 12 A \cdots \mathrm{N} 1 \mathrm{~S} 2.53, \angle \mathrm{CHN} 151 \\
\mathrm{C} 14 \mathrm{H} 14 B \cdots \mathrm{N} 1 \mathrm{~S} 2.60, \angle \mathrm{CHN} 149\end{array}$ \\
\hline
\end{tabular}

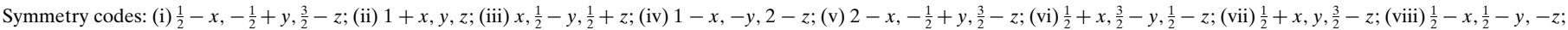
(ix) $1-x,-y,-z$; (x) $-1+x, 1+y, z$; (xi) $1+x, y, z$; (xii) $-x,-y,-z$; (xiii) $-x, 1-y,-z$.

\subsection{Extended structures}

Intermolecular geometry parameters for (1)-(5) are listed in Table 3 .

3.3.1. $\left[\mathrm{Co}\left(\mathrm{C}_{6} \mathbf{H}_{12} \mathrm{~S}_{3}\right)_{2}\right]^{3+} \cdot \mathbf{3 I}_{3}^{-} \cdot \mathbf{I}_{\mathbf{2}}$ (1). By considering $\mathrm{I} \cdots \mathrm{I}$ contacts of up to $4.0 \AA$, it is possible to construct twisted rings each containing $11 \mathrm{I}$ atoms (Fig. 6). Each ring comprises three tri-iodide anions and one di-iodine molecule and in addition to the bonded distances described in $\$ 3.2 .1$ its assembly requires two I3 $\cdots$ I6 contacts of 3.384 (2) $\AA$ and two I1 $\cdots$ I5 $\left(\frac{1}{2}-x\right.$, $\left.-\frac{1}{2}+y, \frac{3}{2}-z\right)$ contacts of 3.905 (2) $\AA$. It is possible to visualize cages around the cations by invoking longer I - . I contacts of up to $4.15 \AA$ between the 11 -membered rings, but this construction is unconvincing and inelegant. In contrast, considering S1 . II interactions of 3.709 (2) A between the I1 atoms in these 11-membered polyhalide rings and the S1 atoms of the macrocyclic cation allows the extended structure to be visualized as undulating chains comprised of alternating $\mathrm{I}_{11}^{3-}$ rings and complex cations running along the [101] direction (Fig. 6). Each cation is linked to two polyiodide rings, with all S1 $\cdots$ I1 interactions being equivalent. Interestingly, very similarly shaped 14-membered polyhalide rings are formed at the $\left.\left[(16] \mathrm{aneS}_{4}\right) M-\mathrm{I}-M\left([16] \mathrm{aneS}_{4}\right)\right]^{3+}$ cation template $[M=$ $\left.\mathrm{Pd}^{\mathrm{II}}, \mathrm{Pt}^{\mathrm{II}}\right]$. These comprise two L-shaped $\mathrm{I}_{5}^{-}$and two $\mathrm{I}^{-}$ interacting units and their symmetry repeats (Blake, Lippolis

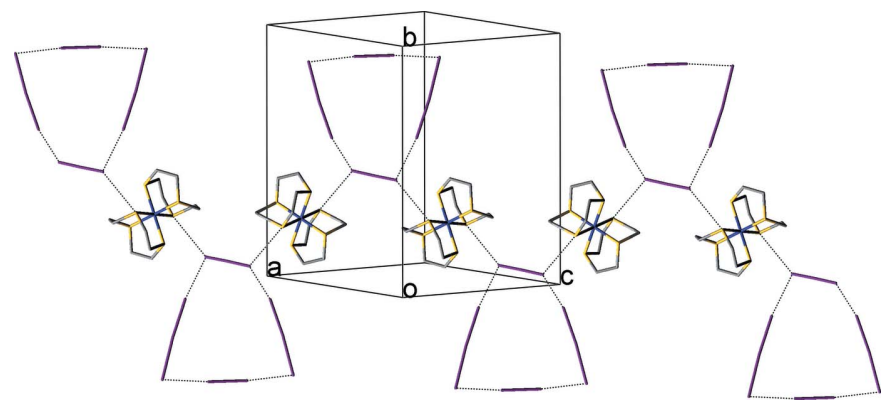

Figure 6

The extended structure of (1) exhibits 11 -membered iodine rings. S $\cdots I$ interactions between these rings and the $\mathrm{S} 1$ atoms of the macrocyclic cation lead to the formation of undulating chains comprised of alternating $\mathrm{I}_{11}^{3-}$ rings and complex cations running along the [101] direction. et al., 1996). However, rather than being isolated, in this case the polyhalide rings are fused by sharing three iodide atoms, and each forms a belt around the binuclear metal cation with the $\mathrm{I}^{-}$of the $M-\mathrm{I}-M$ bridge placed exactly at the centre.

3.3.2. $\left[\mathrm{Ni}\left(\mathrm{C}_{6} \mathrm{H}_{12} \mathrm{~S}_{3}\right)_{2}\right]^{2+} \cdot 2 \mathrm{I}_{3}^{-}$(2). There are no significant interactions of the type I $\cdots$ I between the tri-iodide anions, but there are two different S...I contacts. If only the slightly shorter of these [3.769(2) $\AA$ ] is considered, each $\left[\mathrm{Ni}\left([9] \mathrm{aneS}_{3}\right)_{2}\right]^{2+}$ cation is linked to two tri-iodide anions by $\mathrm{S} 7 \cdots \mathrm{I} 3(1+x, y, z)$ interactions and there is no extended structure. However, taking into account the slightly longer S4 $\cdots \mathrm{I} 2\left(x, \frac{1}{2}-y, \frac{1}{2}+z\right)$ contact of 3.796 (2) $\AA$ reveals well separated sheets of cations and anions (Fig. 7), as seen previously in the isomorphous cobalt(II) salt $\left[\mathrm{Co}\left(\mathrm{C}_{6} \mathrm{H}_{12} \mathrm{~S}_{3}\right)_{2}\right]^{2+} \cdot 2 \mathrm{I}_{3}^{-}$(Blake, Lippolis et al., 1998). These two contacts are supplemented by longer S...I contacts of 3.983 (2) and 3.970 (2) $\AA$ : as in each case the latter involve the other macrocycle in the same cation, they do not affect the dimensionality of the structure. It is interesting to note that the $\mathrm{I}_{3}^{-}$salts of metal complexes of thioether macrocyclic ligands synthesized so far (all by metathesis) generally show isolated $\mathrm{I}_{3}^{-}$units (Blake, Gould et al., 1999; Blake, Gould et al., 1998). Extended structures are formed via S...I or $M \cdots$ I interactions with the complex metal cations. Exceptions are the compounds $\left[\mathrm{Pd}_{2} \mathrm{Cl}_{2}\left([18] \mathrm{aneN}_{2} \mathrm{~S}_{4}\right)\right]\left(\mathrm{I}_{3}\right)_{2}$ (Blake, $\mathrm{Li}$, Lippolis, Parsons \& Schröder, 1998) and $[\operatorname{Pd}($ cis$\left.\left.\mathrm{HO})_{2}[14] \mathrm{aneS}_{4}\right)\right]\left(\mathrm{I}_{3}\right)_{2}$ (Blake, Gould et al., 1999), in which poly- $\mathrm{I}_{3}^{-}$chains and puckered layers, respectively, are formed via $\mathrm{I} \cdots \mathrm{I}$ interactions.

3.3.3. $\left[\mathrm{Ni}\left(\mathrm{C}_{6} \mathrm{H}_{12} \mathrm{~S}_{3}\right)_{2}\right]^{\mathbf{2 +}} \cdot \mathbf{2}_{5}^{-}$(3). In (3) the $\mathrm{I}_{5}^{-}$anions are linked by $\mathrm{I} 5 \cdots \mathrm{I} 1\left(\frac{1}{2}+x, \frac{3}{2}-y, \frac{1}{2}-z\right)$ contacts of 3.799 (2) $\AA$ into helices with a pitch of 12.317 (3) $\AA$ running along the $a$ axis, as shown in Fig. 8. The helices are cross-linked by S4 $\cdots \mathrm{I} 3\left(\frac{1}{2}+x, y, \frac{3}{2}-z\right)$ contacts of 3.771 (2) $\AA$ to give sheets of helices and cations which lie in the (021) plane. Each cation forms one S. . I contact from each of its macrocyclic ligands to a neighbouring helix. The cations are clearly located outside the manifold of the helices. Helical or double helical arrays of polyiodide anions are quite rare, the only known examples being obtained by self-assembly at helical cation templates 
with the transfer of geometrical properties (helicity) from one crystal component to the other mediated by hydrogenbonding interactions (Horn, Blake, Champness, Garau et al., 2003; Horn, Blake, Champness, Lippolis \& Schröder, 2003). In this case, the $\left[\mathrm{Ni}\left([9] \mathrm{aneS}_{3}\right)_{2}\right]^{2+}$ cation is able to direct a helical catenation of the $\mathrm{I}_{5}^{-}$units via $\mathrm{S}$. I I interactions.

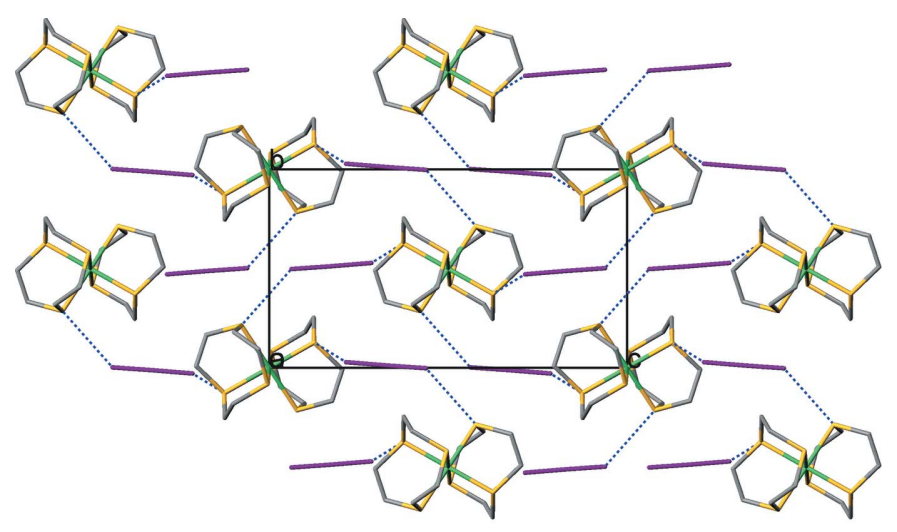

(a)

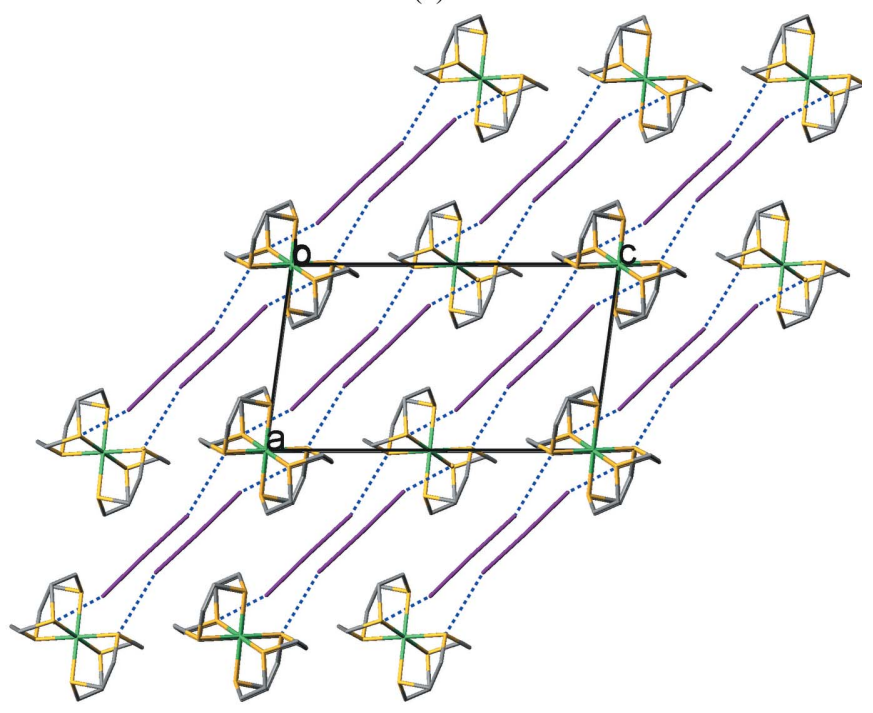

(b)

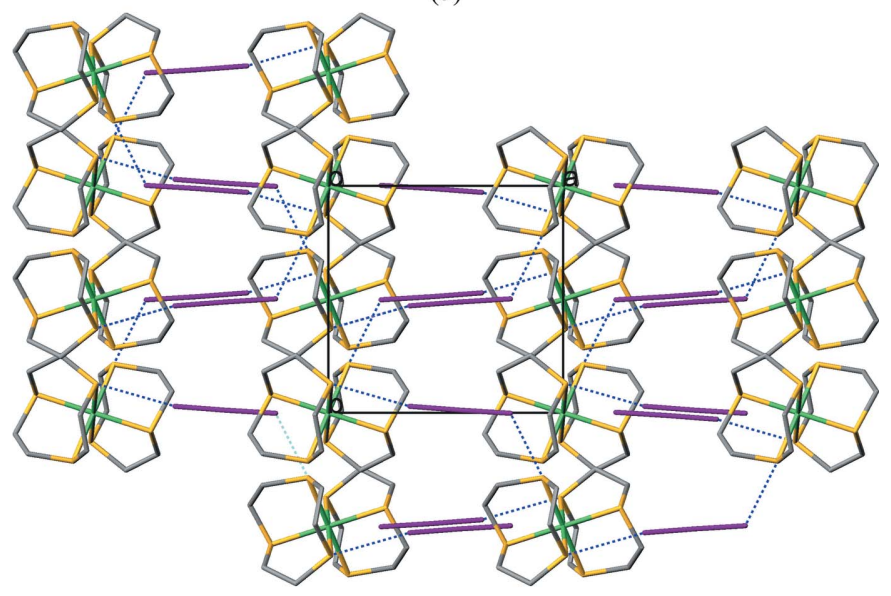

(c)

Figure 7

Three views of the well separated sheets of cations and anions linked by $\mathrm{S} \cdots \mathrm{I}$ interactions in (2), along the (a) $a,(b) b$ and (c) $c$ directions.
3.3.4. $\left[\operatorname{Pd}\left(\mathrm{C}_{\mathbf{8}} \mathrm{H}_{16} \mathrm{~S}_{4}\right)\right]^{2+} \cdot \mathbf{2} \mathrm{I}_{3}^{-}$(4). The disorder in the complex cation may be due to the poor size match between it and the voids in the polyiodide network formed by the disposition of the $\mathrm{I}_{3}^{-}$units of each disorder component within the lattice. This situation raises questions as to the precise nature of the templating unit and the importance, in this respect, of the $M \cdots \mathrm{I}$ and $\mathrm{S} \cdots \mathrm{I}$ interactions. The following discussion refers

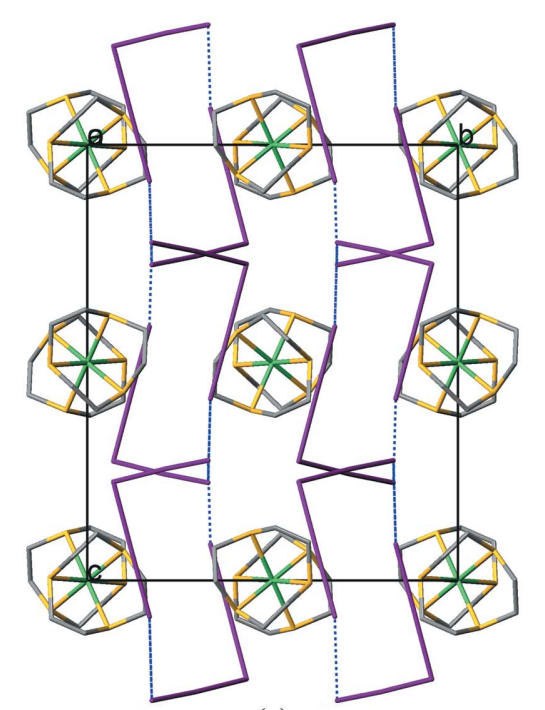

(a)

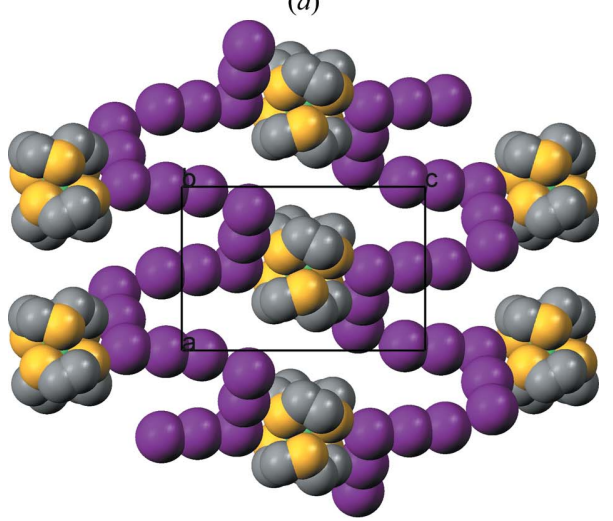

(b)

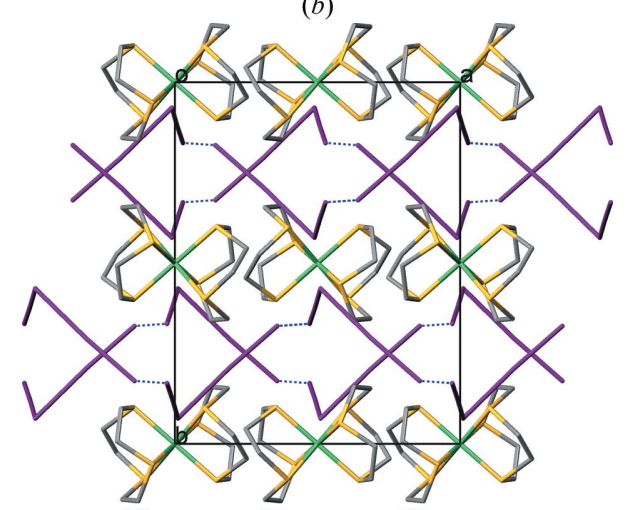

(c)

Figure 8

Three views of the extended structure of (3), along the (a) $a,(b) b$ and (c) $c$ directions. The view along $a$ is parallel to the helical axis and shows the relationship of the helices and the cations; the view along $b$ is a spacefilling plot showing the helices running along the $a$ direction and crosslinked by S...I interactions; the view along $c$ provides an orthogonal aspect of the helices and cations. 
to the major component only. The structure contains no I . . I contacts below $4.0 \AA$. At this level the $\mathrm{I}_{3}^{-}$could be considered isolated in the lattice (as is normally found, see above), but longer contacts [I $\cdots \mathrm{I} 6\left(\frac{1}{2}-x, \frac{1}{2}-y,-z\right) 4.036(3), \mathrm{I} 1 \cdots \mathrm{I} 8$

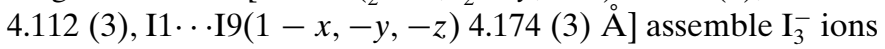

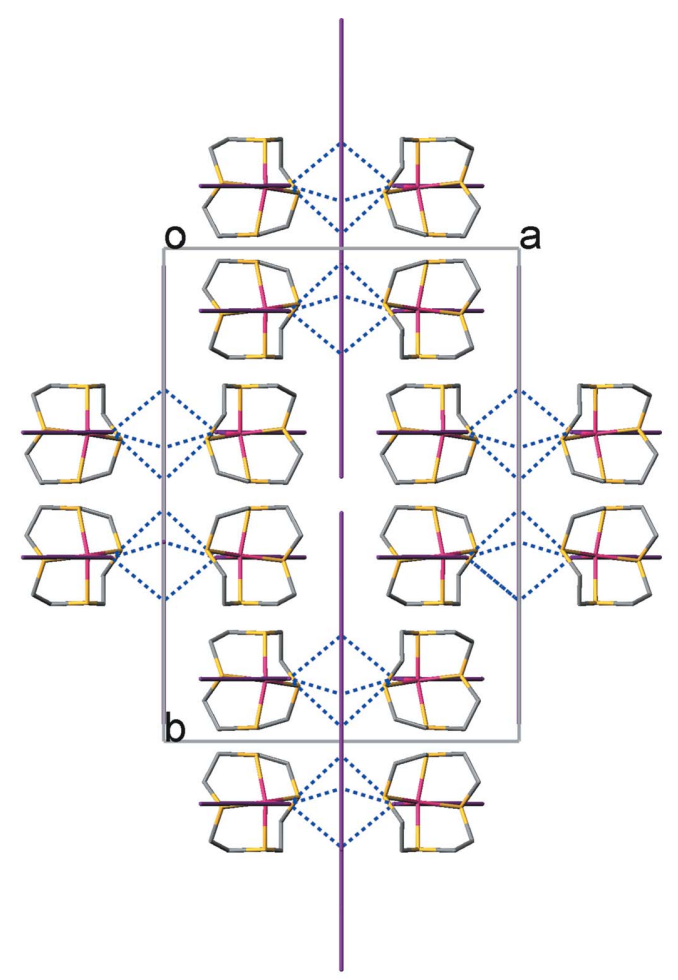

(a)

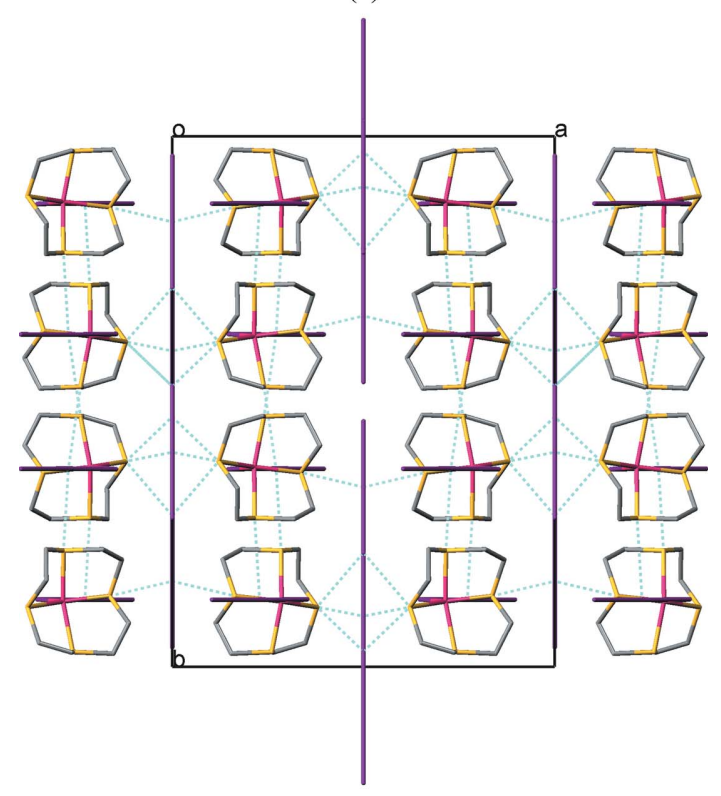

(b)

\section{Figure 9}

Two views of the extended structure of (4), both along the $c$ axis. The upper view shows how long I...I contacts of $4.036(3), 4.112$ (3) and 4.174 (3) A (shown as blue dotted lines) assemble ions into $2 \times 2$ rods running along the $c$ axis. The lower view shows how the three-dimensional network is built up by S...I contacts (shown in cyan) between the rods. into $2 \times 2$ rods running along the $c$ axis (Fig. 9, upper view). Respective S10 $\cdots$ I5 and S4 $\cdots$ I9 $(1-x,-y,-z)$ contacts of 3.561 (3) and 3.639 (3) $\AA$ result in a three-dimensional network, as shown in the lower view in Fig. 9.

3.3.5. $\left[\mathrm{Pd}\left[\mathrm{C}_{10} \mathbf{H}_{20} \mathrm{~S}_{4}\right)\right]^{2+} \cdot \mathbf{2}_{5}^{-} \cdot \mathrm{C}_{2} \mathbf{H}_{3} \mathbf{N}$ (5). The main feature of this extended structure is the corrugated, zigzag chains of polyiodide rings formed by linked $\mathrm{I}_{5}^{-}$units running along the $b$ axis (Fig. 10, upper view). The polyiodide network is built up from $\mathrm{I}_{5}^{-}$anions connected through $\mathrm{I} \cdots \mathrm{I}$ contacts of 3.543 (2), 3.913 (2) and 4.179 (2) $\AA$ for I6 $\cdots \operatorname{I10}(1-x,-y, 1-z)$, $\mathrm{I} 5 \cdots \mathrm{I} 6(1-x,-y, 1-z)$ and $\mathrm{I} 1 \cdots \mathrm{I} 6(1-x, 1-y, 1-z)$, respectively, which form the polyiodide rings, while I1 $\cdots$ I $8(-1+x, 1+y, z)$ contacts of 3.693 (2) $\AA$ connect the rings to form chains. Metal complex units are attached to the polyiodide network by S...I contacts which then join the chains to form layers: thus, the polyiodide chains are linked not by $\mathrm{I} \cdots \mathrm{I}$ contacts, but by S $\cdots \mathrm{I}$ interactions $[\mathrm{S} 1 \cdots \mathrm{I} 2(1+x$, $y, z) 3.771(2), \mathrm{S} 4 \cdots \mathrm{I} 2(-x,-y,-z) 3.775(2), \mathrm{S} 8 \cdots \mathrm{I} 3(-x$, $1-y,-z) 3.754$ (2) $\AA$ ]. The first of these is supplemented by a somewhat longer S8...I4 $(1+x, y, z)$ interaction of 3.887 (2) §. An additional linkage occurs through solvent molecules hydrogen bonded to the complex cations. The methyl group of the acetonitrile is embedded in the polyiodide network: the individual $\mathrm{C}-\mathrm{H} \cdots \mathrm{I}$ contact geometries $(\mathrm{I} \cdots \mathrm{H}$ 3.305-3.654 $\mathrm{A} ; \quad \mathrm{C}-\mathrm{H} \cdots \mathrm{I} \quad 114-133^{\circ}$ ) are not particularly convincing for hydrogen bonding and it is probably better to describe the situation as a positively charged methyl group lying within a polyanionic region. Overall, these interactions generate a three-dimensional network. Interestingly, the location of the solvent molecules in the middle of the tenmembered polyiodide rings formed by linked $\mathrm{I}_{5}^{-}$units (Fig. 10, middle view) suggests that they have a role as a template for this polyanionic structure, as shown by a space-filling diagram (Fig. 11). In (5) the acetonitrile molecule linked to the $\left[\mathrm{Pd}\left([14] \mathrm{aneS}_{4}\right)\right]^{2+}$ cation via $\mathrm{C}-\mathrm{H} \cdots \mathrm{N}$ interactions seems to play the same template role with respect to the polyiodide network as does the binuclear [(16]ane $\left.\mathrm{S}_{4}\right) M-\mathrm{I}-$ $M\left([16]\right.$ aneS $\left.\left._{4}\right)\right]^{3+}$ cation in $\left\{\left[M\left([16] \mathrm{aneS}_{4}\right)\right]_{2} \mathrm{I}\right\} \mathrm{I}_{11}\left(M=\mathrm{Pd}^{\mathrm{II}}, \mathrm{Pt}^{\mathrm{II}}\right.$; Blake, Lippolis et al., 1996). The final view in Fig. 10 is along the $c$ axis and illustrates the I...I and S. .I interactions and the corrugation of the polyiodide sheets of linked poly $\mathrm{I}_{5}^{-}$ rings.

\section{FT-Raman spectroscopy}

The crystal structure determinations indicate that all the higher polyiodide species $\mathrm{I}_{2 m+n}^{n-}$ may be regarded as weak or medium-weak adducts of the types $\left[\left(\mathrm{I}^{-}\right)_{n-y}\left(\mathrm{I}_{3}{ }^{-}\right)_{y} \cdot\left(\mathrm{I}_{2}\right)_{m-y}\right]$, where $m$ is the number of di-iodine molecules and $n$ is the number of $\mathrm{I}^{-}$anions, which can be present as $\mathrm{I}_{3}^{-}$. In the absence of a crystal structure determination, FT-Raman spectroscopy can differentiate between the first type of polyiodide $\left[\left(\mathrm{I}^{-}\right)_{n} \cdot\left(\mathrm{I}_{2}\right)_{m}\right](y=0)$, and the other two $\left[\left(\mathrm{I}_{3}^{-}\right)_{n} \cdot\left(\mathrm{I}_{2}\right)_{m-n}\right]$ $(n=y \neq 0),\left[\left(\mathrm{I}^{-}\right)_{n-y} \cdot\left(\mathrm{I}_{3}^{-}\right)_{y} \cdot\left(\mathrm{I}_{2}\right)_{m-y}\right](n>y \neq 0)$, depending on the absence or presence in the spectrum of the characteristic peaks due to $\mathrm{I}_{3}^{-}$anions. A single band near $110 \mathrm{~cm}^{-1}\left(v_{1}\right)$ is expected for a symmetric $\mathrm{I}_{3}^{-}$ion, whereas slightly asymmetric 
tri-iodides exhibit two additional bands near $130\left(v_{3}\right)$ and $80 \mathrm{~cm}^{-1}\left(v_{2}\right)$ with medium to weak intensities (Deplano et al., 1994). For all three types of polyiodide adduct described above, each elongated $\mathrm{I}_{2}$ molecule will show only one band in

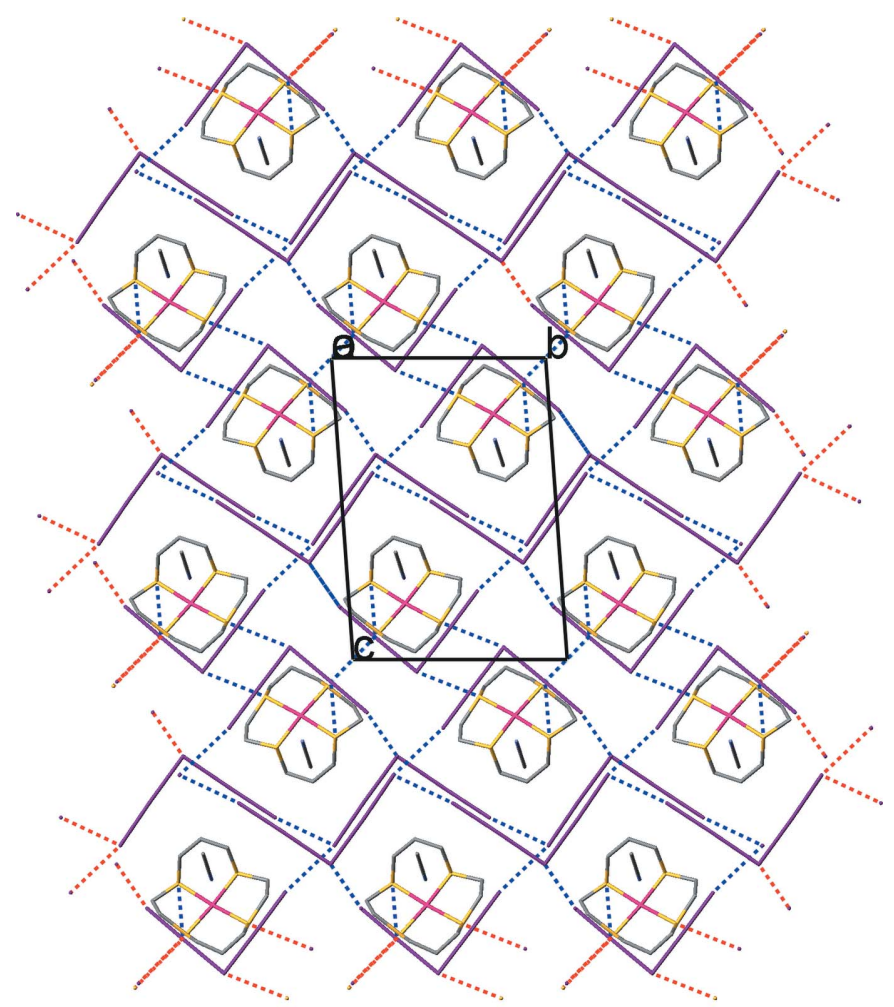

(a)

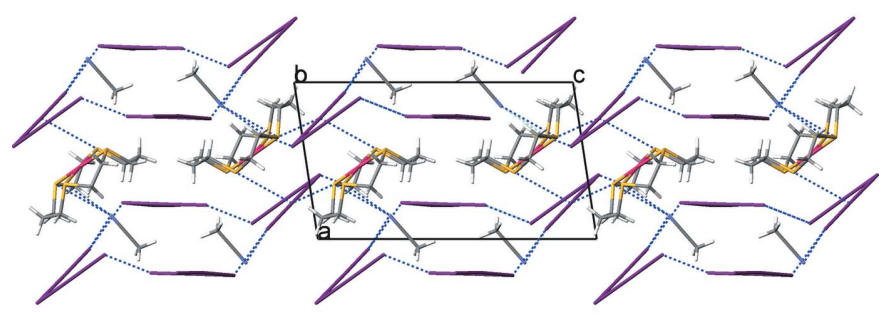

(b)

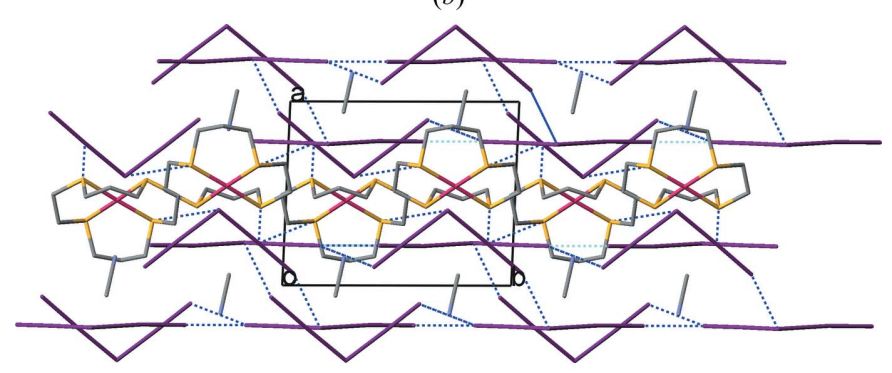

(c)

Figure 10

The top view of (5) is a projection along the $a$ axis illustrating the zigzag chains of iodine rings formed by linked $\mathrm{I}_{5}^{-}$units running along the $b$ axis and the $\mathrm{S} \cdots \mathrm{I}$ linkages which attach the cations to the polyiodide network, which assemble the chains into sheets. The middle view along the $b$ axis shows the S...I interactions between the polyiodide sheets and the complex cation leading to a three-dimensional network, and $\mathrm{C}-\mathrm{H} \cdots \mathrm{N}$ interactions between the complex cation and the solvent molecule. The bottom view along the $c$ axis is an alternative illustration of the I $\cdots I$ and S...I interactions and the corrugation of the polyiodide layers. the FT-Raman spectrum [the $v(\mathrm{I}-\mathrm{I})$ stretching vibration] in the approximate range $180-150 \mathrm{~cm}^{-1}$, the exact value depending on the degree of I-I bond elongation (Deplano et al., 1992). However, FT-Raman spectroscopy cannot provide any structural information on the topological features of an extended polyiodide network, because the technique can only detect the presence of $\mathrm{I}_{3}^{-}$anions and slightly elongated diiodine molecules, along with some information on the degree of distortion and elongation of these two units, respectively. In this respect, the structural features of the reported polyiodides are consistent with their FT-Raman spectra. Compounds (2) and (4) each show in their FT-Raman spectra two peaks at 129, 113 and $125,110 \mathrm{~cm}^{-1}$, respectively, which can be assigned to the antisymmetric and symmetric stretching vibrations, respectively, of the slightly asymmetric tri-iodides. The two peaks observed in the spectrum of (3) at 164.2 and $145.4 \mathrm{~cm}^{-1}$ can be assigned to the stretching vibrations of the differently perturbed di-iodine molecules constituting the $\mathrm{I}_{5}^{-}$fragments describable as $\left[\mathrm{I}^{-} \cdot\left(\mathrm{I}_{2}\right)_{2}\right]$ adducts. The peak at $109.5 \mathrm{~cm}^{-1}$ observed in the FT-Raman spectrum of (1) can be assigned to

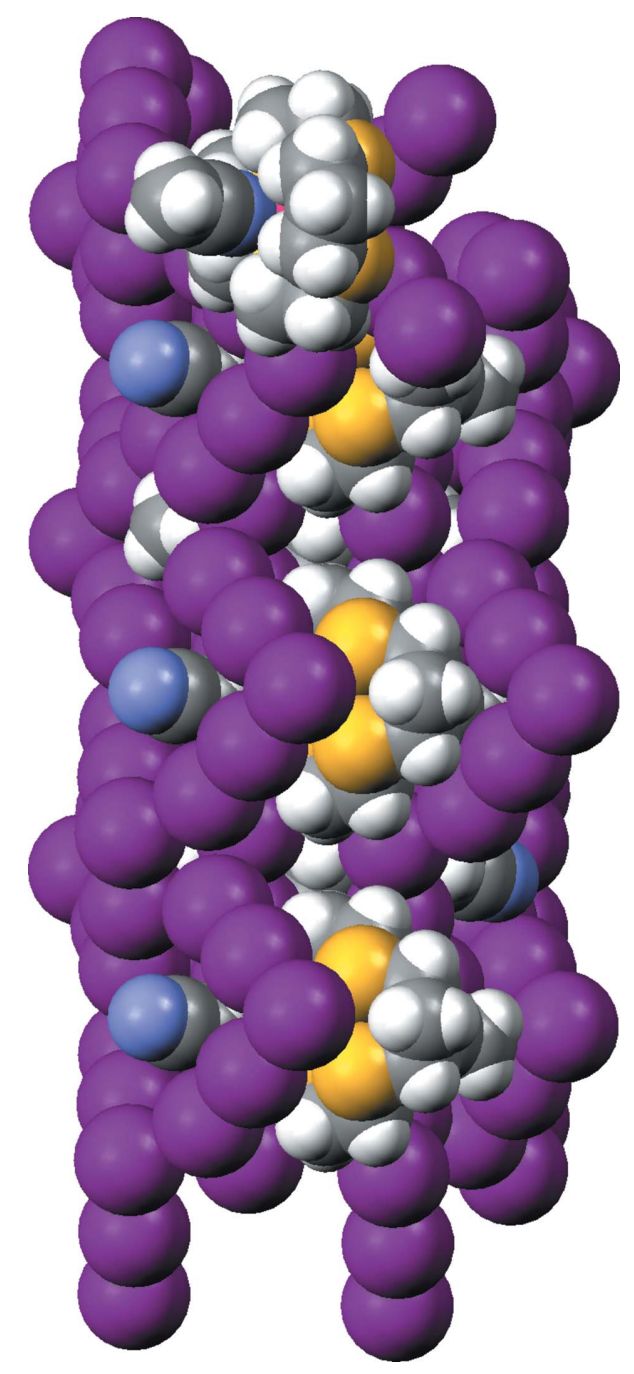

Figure 11

A space-filling view of (5), illustrating the possible role of solvent molecules as a template for this polyanionic structure. 
the symmetric $\mathrm{I}_{3}^{-}$present in the crystal structure, while the other two peaks at 168.2 and $149.9 \mathrm{~cm}^{-1}$ can be assigned to the stretching vibrations of the two differently perturbed di-iodine molecules, one of which (I4-I5) interacts with $\mathrm{I} 3$ to give a very asymmetric $\mathrm{I}_{3}^{-}$which can be described as an $\left[\mathrm{I}^{-} \cdot \mathrm{I}_{2}\right]$ adduct. The peaks at 168.9, 163.2 and $154.5 \mathrm{~cm}^{-1}$ observed in the FT-Raman spectrum of (5) can be assigned, respectively, to the stretching vibrations of the perturbed di-iodine molecules I9-I10, I6-I7, I1-I2 and I4-I5 belonging to the $\mathrm{I}_{5}^{-}$anions. The peak at $115.7 \mathrm{~cm}^{-1}$ is attributed to a symmetric $\mathrm{I}_{3}^{-}$formed by decomposition of the sample under laser irradiation.

\section{Concluding remarks}

The combination of (Lewis acidic) molecular di-iodine with (Lewis basic) iodide or tri-iodide anions to form extended donor-acceptor arrays is a remarkable example of selfassembly. Over the last 10 years we have established the great flexibility of polyiodide catenation to produce networks of varying topology by templation about a range of metal complexes of thioether macrocycles differing in charge, shape and size. At this stage some general conclusions can be drawn:

(i) From a synthetic point of view the best approach is to react a $\mathrm{BF}_{4}^{-}$or $\mathrm{PF}_{6}^{-}$salt of the metal complex with excess diiodine with the preferred polyiodide species being formed by self-assembly. Metathesis reactions using preformed $\mathrm{I}_{3}^{-}$or $\mathrm{I}_{5}^{-}$ ions generally afford compounds in which the polyiodide units (normally tri-iodides) are isolated and rarely form extended structures through short I $\cdots$ I contacts.

(ii) An effective direct transfer of geometrical properties (templation) from one crystal component (cation) to the other (polyiodide network) has been frequently observed, and is generally determined by the shape and charge of the cation template and directed by $\mathrm{H} \cdots \mathrm{I}$ interactions.

(iii) Long S $\cdots \mathrm{I}$ and $M \cdots \mathrm{I}$ contacts can tip the balance towards polyiodide arrays of lower dimensionality and different geometry than would be expected on the basis of the shape of the complex cation template.

(iv) $\mathrm{S} \cdots \mathrm{I}$ and $M \cdots \mathrm{I}$ contacts, which are very common in products of metathesis reactions, frequently hamper the formation of multi-dimensional polyiodide networks. In these cases the extended structure involves both the cation and the anion.

Although we were able to draw the conclusions (i)-(iv) above in previous papers, we were only able to do so in a preliminary manner. The present work has, therefore, greatly contributed to defining more precisely the border between the different outcomes that can be expected from metathesis reactions versus those resulting from using excess iodine. Owing to the nature of the various interactions involved, exceptions to general trends are always possible and it is for this reason that the study of additional structures is necessary to obtain confirmation of the general relevance of conclusions (i)-(iv). We therefore selected for both metathesis and excess iodine reactions those metal cations which, according to our experience of earlier reactions, offered a good variability in shape, charge and size.
The use of stable metal complexes of macrocyclic ligands to provide a range of cationic templates is an especially promising strategy. It fulfils the four general requirements (i)(iv) set out in the previous paragraph and will provide further insight into the factors that determine templation in the selfassembly of polyiodide arrays.

We thank EPSRC for funding of diffractometers and for access to the Chemical Database Service at Daresbury Laboratory (Fletcher et al., 1996). MS acknowledges receipt of a Royal Society Leverhulme Trust Senior Research Fellowship and a Royal Society Wolfson Merit Award.

\section{References}

Allen, F. H., Johnson, O., Shields, G. P., Smith, B. R. \& Towler, M. (2004). J. Appl. Cryst. 37, 335-338.

Altomare, A., Burla, M. C., Camalli, M., Cascarano, G., Giacovazzo, C., Guagliardi, A. \& Polidori, G. (1994). J. Appl. Cryst. 27, 435.

Aragoni, M. C., Arca, M., Demartin, F., Devillanova, F. A., Garau, A., Isaia, F., Lippolis, V., Rizzato, S. \& Verani, G. (2004). Inorg. Chim. Acta, 357, 3803-3809.

Aragoni, M. C., Arca, M., Devillanova, F. A., Isaia, F., Lippolis, V., Mancini, A., Pala, L., Slawin, A. M. Z. \& Woollins, J. D. (2003). Chem. Commun. pp. 2226-2227.

Bell, M. N., Blake, A. J., Gould, R. O., Holder, A. J., Hyde, T. I., Lavery, A. J., Reid, J. \& Schröder, M. (1987). J. Incl. Phenom. 5, 169-172.

Blake, A. J., Brooks, N. R., Champness, N. R., Hubberstey, P., Keppie, I. J., Schröder, M. \& Marr, A. C. (2001). Acta Cryst. E57, m376m377.

Blake, A. J., Devillanova, F. A., Garau, A., Gilby, L. M., Gould, R. O., Isaia, F., Lippolis, V., Parsons, S., Radek, C. \& Schröder, M. (1998). J. Chem. Soc. Dalton Trans. pp. 2037-2046.

Blake, A. J., Devillanova, F. A., Gould, R. O., Li, W.-S., Lippolis, V., Parsons, S., Radek, C. \& Schröder, M. (1998). Chem. Soc. Rev. 27, 195-205.

Blake, A. J., Gould, R. O., Li, W.-S., Lippolis, V., Parsons, S., Radek, C. \& Schröder, M. (1998). Inorg. Chem. 37, 5070-5077.

Blake, A. J., Gould, R. O., Li, W.-S., Lippolis, V., Parsons, S. \& Schröder, M. (1999). Crystal Engng, 2-3, 153-170.

Blake, A. J., Gould, R. O., Parsons, S., Radek, C. \& Schröder, M. (1995). Angew. Chem. Int. Ed. Engl. 34, 2374-2376.

Blake, A. J., Holder, A. J., Reid, G. \& Schröder, M. (1994). J. Chem. Soc. Dalton Trans. pp. 627-631.

Blake, A. J., Li, W.-S., Lippolis, V., Parsons, S., Radek, C. \& Schröder, M. (1998). Angew. Chem. Int. Ed. Engl. 37, 293-296.

Blake, A. J., Li, W.-S., Lippolis, V., Parsons, S. \& Schröder. M. (1998). Acta Cryst. C54, 1408-1410.

Blake, A. J., Lippolis, V., Parsons, S. \& Schröder, M. (1996). Chem. Commun. pp. 2207-2208.

Blake, A. J., Lippolis, V., Parsons, S. \& Schröder, M. (1998). Acta Cryst. C54, 293-295.

Blake, A. J. \& Schröder, M. (1990). Adv. Inorg. Chem. 35, 1-80.

Bolhuis, F. van, Koster, P. B. \& Migchelsen, T. (1967). Acta Cryst. 23, 90-91.

Bruker (2001). SHELXTL, Version 6.12. Bruker AXS, Madison, Wisconsin, USA.

Clegg, W. (1981). Acta Cryst. A37, 22-28.

Cosier, J. \& Glazer, A. M. (1986). J. Appl. Cryst. 19, 105-107.

Deplano, P., Devillanova, F. A., Ferraro, J. R., Isaia, F., Lippolis, V. \& Mercuri, M. L. (1992). Appl. Spectrosc. 46, 1625-1629.

Deplano, P., Devillanova, F. A., Ferraro, F., Lippolis, V., Mercuri, M. L. \& Trogu, E. F. (1994). Appl. Spectrosc. 48, 1236-1241. 
Fletcher, D. A., McMeeking, R. F. \& Parkin, D. (1996). J. Chem. Inf. Comput. Sci. 36, 746-749.

Horn, C. J., Blake, A. J., Champness, N. R., Garau, A., Lippolis, V., Wilson, C. \& Schröder, M. (2003). Chem. Commun. pp. 312-313.

Horn, C. J., Blake, A. J., Champness, N. R., Lippolis, V. \& Schröder, M. (2003). Chem. Commun. pp. 1488-1489.

Kirin, D. (1987). Acta Cryst. B43, 405-406.

Küppers, H.-J., Neves, A., Pomp, C., Ventur, D., Weighardt, K., Nuber, B. \& Weiss, J. (1986). Inorg. Chem. 25, 2400-2408.

Macrae, C. F., Edgington, P. R., McCabe, P., Pidcock, E., Shields, G. P., Taylor, R., Towler, M. \& van de Streek, J. (2006). J. Appl. Cryst. 39, 453-457.

Nishijo, J., Miyazaki, A. \& Enoki, T. (2004). Bull. Chem. Soc. Jpn, 77, 715-727.
North, A. C. T., Phillips, D. C. \& Mathews, F. S. (1968). Acta Cryst. A24, 351-359.

Setzer, W. N., Ogle, C. A., Wilson, G. S. \& Glass, R. S. (1983). Inorg. Chem. 22, 266-271.

Sheldrick, G. M. (1990). Acta Cryst. A46, 467-473.

Sheldrick, G. M. (1998). SHELXL97-2. University of Göttingen, Göttingen, Germany.

Spek, A. L. (2003). J. Appl. Cryst. 36, 7-13.

Stoe \& Cie (1996a). Stadi-4. Stoe \& Cie, Darmstadt, Germany.

Stoe \& Cie (1996b). X-RED. Stoe \& Cie, Darmstadt, Germany.

Svenson, P. H. \& Kloo, L. (2003). Chem. Rev. 103, 16491684.

Tebbe, K.-F. \& Buchem, R. (1997). Angew. Chem. Int. Ed. Engl. 36, $1345-1346$. 